\title{
Ecological compensation for winter wheat abandonment in groundwater over-exploited areas in the North China Plain
}

\author{
WANG Xue ${ }^{1,2},{ }^{*}$ LI Xiubin ${ }^{1}$, XIN Liangjie ${ }^{1}$, TAN Minghong ${ }^{1}$, LI Shengfa ${ }^{1,2}$, \\ WANG Renjing ${ }^{1,2}$ \\ 1. Key laboratory of Land Surface Pattern and Simulation, Institute of Geographic Sciences and Natural Re- \\ sources Research, CAS, Beijing 100101, China; \\ 2. University of Chinese Academy of Sciences, Beijing 100049, China
}

\begin{abstract}
The land fallow policy was adopted by central and local governments to encourage the abandonment of water-intensive crops, such as winter wheat, in groundwater over-exploited areas. At the same time, since the 1990s, many households in the North China Plain (NCP) have chosen to replace the winter wheat and summer maize double-cropping system with the spring maize single-cropping system. Therefore, it is crucial to identify target land parcels for winter wheat abandonment and to design reasonable and proper standards for ecological compensation prior to the implementation of the land fallow policy in the NCP. In this study, multi-level logit models were used with household survey data in order to detect determinants across land parcel, household and village levels on household cropping system decisions; the opportunity costs for winter wheat abandonment were also calculated using cost-benefit analysis. The results show that: (1) land quality and irrigation condition at parcel level are two essential elements influencing household cropping system decisions. Nearly $70 \%$ of the total area of poor land and more than $90 \%$ of the total area of unirrigated land has suffered winter wheat abandonment. Target land parcels for the land fallow policy should be those that are irrigated and of high quality. (2) There were no significant differences between net profits from spring maize and summer maize under similar farming conditions, and the opportunity cost for winter wheat abandonment should be equal to the net profit of winter wheat. (3) The primary purpose of the land fallow policy is to induce groundwater recovery and restoration as a preliminary stage. A higher level of $350 \mathrm{yuan} / \mathrm{mu}$ is recommended as subsidy for ecological compensation at this stage. Later, the primary purpose of the policy should be a transition to a balance between exploitation and supplementation of water resources, and a lower level of $280 \mathrm{yuan} / \mathrm{mu}$ is recommended as a subsidy at this stage.
\end{abstract}

Keywords: land fallow; ecological compensation; multi-level logit model; opportunity cost; groundwater over-exploited areas

Received: 2016-03-09 Accepted: 2016-04-08

Foundation: National Natural Science Foundation of China, No.41571095, No.41271119

Author: Wang Xue, PhD Candidate, specialized in land use change analysis. E-mail: wangx.12b@igsnrr.ac.cn

"Corresponding author: Li Xiubin, Professor, E-mail: lixb@igsnrr.ac.cn 


\section{Introduction}

The North China Plain (NCP) is one of the major food production areas in China. It is also amongst the global "hotspots" in terms of water scarcity (Chen et al., 2003; Gleeson et al., 2012). The conflict between agriculture and water is alarming, and groundwater has been the lifeblood of agriculture here since the 1970s (Cao et al., 2013; Hu et al., 2010). However, the over-exploitation of groundwater in the NCP has had devastating consequences. The shallow groundwater tables have dropped 20-40 m across Hebei and Beijing (Zhang et al., 2009). The groundwater depression cone has been expanding and deepening since the 1970s, forming a bread-like groundwater depression cone in the piedmont plain and a deep composite groundwater cone with an area of $5 \times 10^{4} \mathrm{~km}^{2}$ (Zhang et al., 2009). Groundwater over-exploitation has also caused severe land subsidence and ground fissures. Tianjin, Cangzhou and northwest Beijing are three major centers of land subsidence, and the maximum land subsidence in both Tianjin and Tanggu has exceeded $3.1 \mathrm{~m}$. Many ground-fissure disasters occurred in Hengshui during 2006-2010; of these, the Wuyi-Fucheng fissure was the longest, reaching a length of $8 \mathrm{~km}$ (Kou, 2014). The scale of the problem is such that it is now imperative to find ways to induce groundwater recovery and restoration in the NCP.

Of all the agricultural crops in the NCP, winter wheat has played a key role in the development of water scarcity and the over-exploitation of groundwater, as more than $70 \%$ of irrigation water is consumed by winter wheat (Li et al., 2005; Sun et al., 2010). In comparison, maize consumes less groundwater than winter wheat, as during its growing period in summer and autumn it receives larger volumes of natural precipitation (Sun et al., 2011). Therefore, the land fallow policy, with a reduction in sown areas of winter wheat, should be the most effective way to reduce agricultural water consumption and to improve the groundwater environment.

The government has recently put forward policies and regulations to promote the land fallow policy in groundwater over-exploited areas. In 2014, the rehabilitation of agricultural resources was first proposed by the Central First Document, and the groundwater over-exploited NCP was selected as one of the pilot areas. In November 2015, the government explicitly recommended the land fallow policy as a goal for the upcoming Thirteenth Five-Year Plan for social and economic development. Later, Chairman Xi Jinping confirmed that the groundwater over-exploited NCP would be one of the three land fallow pilot areas, along with heavy-metal-contaminated areas and ecological severely degraded zones. He also elaborated in detail that certain areas of farmland should be identified for the land fallow policy, and that local households should be compensated in the form of food or cash in response to the policy. At the same time, local governments of Beijing and Hebei formulated definite plans to secure the implementation of the land fallow policy. In 2014, the Beijing Municipal Government and the Beijing Municipal Bureau of Agriculture both issued several documents; their major tasks are adjustments in agricultural structure and a reduction in sown areas of high-water-consuming crops. Hebei province also formulated similar plans. In the document The Implementation Program on Pilot Comprehensive Control of Groundwater Over-exploitation in Hebei Province through Agricultural Cropping Structure Adjustments and Water-saving Projects in 2014, the government of Hebei province pinpointed the reduction in sown areas of winter wheat in deep groundwater over-exploited areas, and pre- 
liminarily determined 500 yuan/mu $(15 \mathrm{mu}=1 \mathrm{ha})$ to be the subsidy for the land fallow policy. Generally, the terms of the land fallow policy have been set, and some regions in the NCP have already been forced to reduce sown areas of winter wheat. However, the policy is still in its initial stages, and few studies have been related to it. In-depth analysis is greatly needed, especially on target land parcels and reasonable and proper compensation standards.

At the same time, recent studies have found that cases of households abandoning winter wheat on their own initiative were universal across the NCP during the ten years before the land fallow policy was put forward (Wang et al., 2014). Statistical data have also shown that sown areas of winter wheat have reduced since the late 1990s, and that large, spatially continuous areas which were previously winter wheat and summer maize farmed using the double-cropping system are being replaced by spring corn farmed using the single-cropping system in the NCP (Feng et al., 2007; Huang et al., 2012). Thus, the land fallow policy should exclude land parcels where winter wheat has been abandoned by households on their own initiative. Land parcels that are still used for winter wheat production are the policy targets. Besides this, the designation of reasonable and proper ecological compensation standards is another major task for the land fallow policy (Han and $\mathrm{Yu}, 2014$ ). High subsidies would have a negative effect on the food subsidy policy, causing a loss of winter wheat production and a threat to food security; they would also reduce the cost-effectiveness of the policy and waste public financial funds. The market prices for land transition will also be influenced by high subsidies for the land fallow policy, and the influence may even trigger a series of social problems through rent dissipation ( $\mathrm{Li}, 2014$; $\mathrm{Xu}$ et al., 2004). In comparison, low subsidies may not allow the goals of reducing sown areas of winter wheat and finally reducing the consumption of groundwater resources to be reached. Therefore, it is important for the land fallow policy to pinpoint target land parcels and to implement reasonable and proper standards for ecological compensation in groundwater over-exploited areas in the NCP.

In this paper, a case study was carried out in Cangxian, which is also a pilot county for the comprehensive control of groundwater over-exploitation in Hebei province. Using household survey data collected across Cangxian, we established multi-level logit models to analyze the determinants of household cropping system decisions; the opportunity costs of winter wheat abandonment were also calculated. On this basis, suggestions were given for target land parcels and for ecological compensation standards for the land fallow policy in the NCP.

\section{Materials and methods}

\subsection{Study area}

Cangxian county $\left(116^{\circ} 27^{\prime}-117^{\circ} 09^{\prime} \mathrm{E}, 38^{\circ} 03^{\prime}-38^{\circ} 05^{\prime} \mathrm{N}\right)$ is located to the south of Beijing and Tianjin and to the west of the Bohai Sea (Figure 1), and belongs to a flat transition zone from alluvial plain to coastal plain. The major soil type in Cangxian is sandy, but some areas suffer serious salinization or alkalinization. Cangxian has a temperate monsoon climate, with an annual average temperature of $13^{\circ} \mathrm{C}$ and annual average natural precipitation of 590 $\mathrm{mm}$ (Wang, 2012). A winter wheat-summer maize double-croppng system used to be the major cropping system in Cangxian. However, the area farmed using the spring maize single-cropping system has continued to expand in recent years; winter wheat, summer maize 
and spring maize have now become the three major crop types, accounting for more than $90 \%$ of the total sown areas (GOHPG/ SBHP, 2014).

Cangxian is also located in the Cangzhou deep groundwater depression cone, which is the largest depression cone in Hebei province, with an area of $5551 \mathrm{~km}^{2}$ and a central groundwater depth of about $92 \mathrm{~m}$. According to the document The Implementation Program on Pilot Comprehensive Control of Groundwater Over-exploitation in Hebei Province through Agricultural Cropping Structure Adjustments and Water-saving Projects in 2014, Cangxian is one of the 43 pilot counties for the land fallow policy.

\subsection{Data collection}

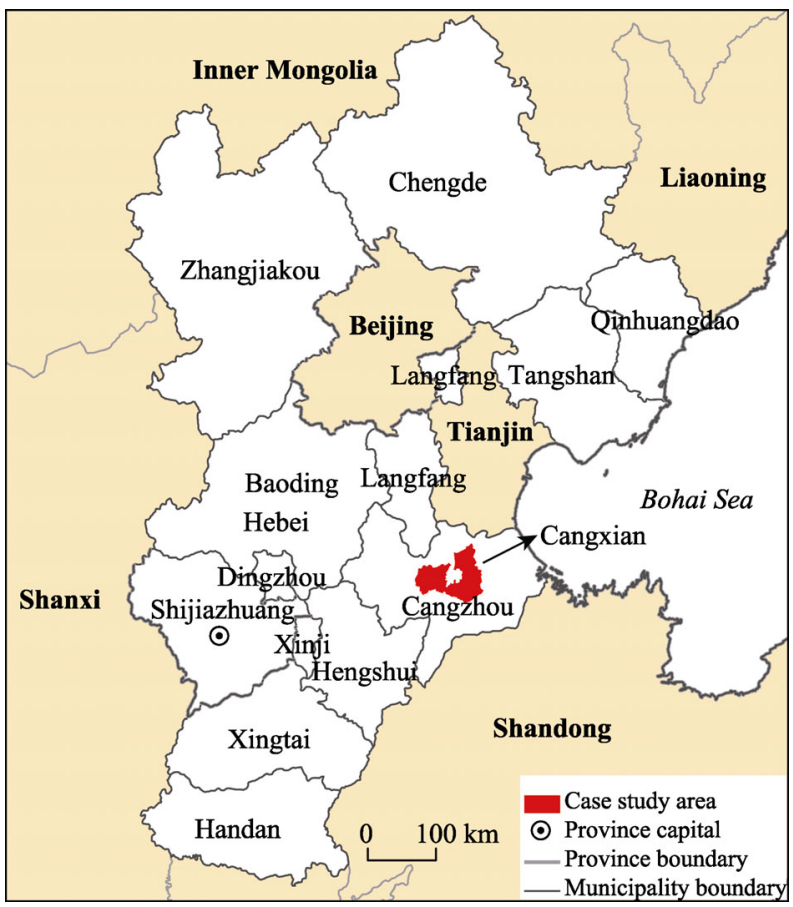

Figure 1 Location of the study area (Cangxian county, Hebei province, China)

The data applied in this study were collected through the household survey in Cangxian during March and May 2015. Household samples were selected by combining the stratified sampling method with the random sampling method (Zhang et al., 2015). We first selected six towns in Cangxian, and then in each town we randomly selected two or three villages with groundwater as the major irrigation water source. In the third step, we randomly selected ten or so households in each village. Questionnaires were completed through semi-structured one-to-one interviews with the household heads or the household members responsible for the farm. The questionnaire contains five sections including household agriculture tools, household demographic characteristics, household income and sources, plot features, and an input-output table for crops during the growth season between 2013 and 2014. In total, 144 households were interviewed, and 134 valid questionnaires were received, with an effective rate being $93.1 \%$.

\subsection{Methodology}

Against the background of households abandoning winter wheat on their own initiative, what are the target land parcels for the land fallow policy? How should we determine the standards for ecological compensation? These are two key issues to be solved during the initial stage of the policy. In order to solve these two issues, the multi-level logit models were established in this study to explore the determinants influencing household cropping system decisions, as well as to pinpoint the major determinants of the spatial distribution of winter wheat. In addition, cost-benefit analysis was carried out to calculate the opportunity cost of winter wheat abandonment, and then to provide suggestions for the standards of ecological compensation for households in response to the policy. 


\subsubsection{Multi-level logit model specification}

According to Yang et al. (2010), household agricultural land-use behaviors are influenced by determinants operating at different levels, such as the physical attributes at land parcel level, economic and labor force characteristics at household level and the location and geographical environment at village level. The aggregated data collected at different levels are always heterogeneous between levels and homogeneous within levels, violating three fundamental assumptions of traditional econometric models, i.e., independent sample, normal distribution and variance homogeneity (Snijders and Boksker, 1999). Multi-level modelling is an effective method in dealing with multi-level data, by decomposing the error term to different levels and transforming error terms to meet the above three assumptions (Overmars and Verburg, 2006). Recently, multi-level modelling has been widely applied in explaining household land-use decisions (Su et al., 2016; Zhang et al., 2014).

In this study, multi-level logit models were applied to analyze the determinants of household cropping system decisions. There were two main cropping systems in Cangxian, i.e., the winter wheat-summer maize double-cropping system (double-cropping system) and the spring maize single-cropping system (single-cropping system). Here, 1 was used to express the double-cropping system, and 0 was used to express the single-cropping system; $p$ was the probability of the occurrence of a "double-cropping system" event. The full three-level logit model was structured as follows:

$$
\log \left(\frac{p_{i j k}}{1-p_{i j k}}\right)=\gamma_{000}+\sum_{n=1}^{N} a_{n 00} X_{n i j k}+\sum_{p=1}^{p} \beta_{0 p 0} Y_{p j k}+\sum_{q=1}^{Q} \delta_{00 q} Z_{q k}+r_{0}+u_{00}
$$

where the subscripts $i, j$ and $k$ are indices of land parcels, households and villages, respectively; $\gamma_{000}$ is the fixed intercept to be estimated; $r_{0}$ and $u_{00}$ are random intercepts at household and village levels, respectively, both conforming to the assumptions of random distribution and mean values of zero; $X, Y$ and $Z$ are explanatory variables at land parcel, household and village levels, respectively; and $\alpha, \beta$ and $\gamma$ are the corresponding regression coefficients.

The intra-class correlation coefficient was estimated in order to indicate the proportion of variance that was explained by a certain level (Zhang et al., 2014).

$$
\rho_{2}=\frac{\operatorname{VAR}\left(r_{0}\right)}{\operatorname{VAR}\left(r_{0}\right)+\operatorname{VAR}\left(u_{00}\right)+\pi^{2} / 3} \rho_{3}=\frac{\operatorname{VAR}\left(u_{00}\right)}{\operatorname{VAR}\left(r_{0}\right)+\operatorname{VAR}\left(u_{00}\right)+\pi^{2} / 3}
$$

where $\rho_{2}$ and $\rho_{3}$ are the intra-class correlation coefficients at household and village levels, respectively; $\operatorname{VAR}\left(r_{0}\right)$ and $\operatorname{VAR}\left(u_{00}\right)$ are the variances of random effects; and $\pi^{2} / 3$ represents the residual variance at land parcel level (Zhang et al., 2014).

In this study, determinants were also selected at three levels including land parcel, household and village levels, and 14 explanatory variables were finally chosen (Table 1).

\subsubsection{Opportunity cost accounting system}

From the perspective of managers, the minimum ecological compensation should be the opportunity cost for the conversation of the ecosystem providing such services, and the maximum should not exceed the total value of the services for their beneficiaries (Laurans et al., 2012). There are three major approaches for determining ecological compensation, i.e., opportunity cost accounting; ecological commodity price determination; and a synthetic 
Table 1 Definition and description of the independent variables

\begin{tabular}{|c|c|c|c|c|c|}
\hline Variable name & Description/definition & Mean & SD & Min & Max \\
\hline \multicolumn{6}{|l|}{ Land parcel level $(\mathrm{n}=521)$} \\
\hline Plot area & Area of the plot $(\mathrm{mu})$ & 2.09 & 1.41 & 0.10 & 11.00 \\
\hline Land quality & $\begin{array}{l}1 \text { good land; } 2 \text { relatively good land; } 3 \text { relatively poor } \\
\text { land; } 4 \text { poor land }\end{array}$ & 1.96 & 0.96 & 1.00 & 4.00 \\
\hline Distance to residence & Distance from the plot to the household residence $(\mathrm{km})$ & 0.84 & 0.55 & 0.05 & 3.00 \\
\hline Irrigation conditions & 1 irrigated land; 0 unirrigated land & 0.85 & 0.36 & 0.00 & 1.00 \\
\hline \multicolumn{6}{|l|}{ Household level $(\mathrm{n}=134)$} \\
\hline Agricultural equipment & 1 with agricultural equipment; 0 without & 0.22 & 0.42 & 0.00 & 1.00 \\
\hline Land fragmentation & $\begin{array}{l}\text { Number of land parcels against total farmland area of the } \\
\text { household }\end{array}$ & 0.51 & 0.21 & 0.17 & 1.35 \\
\hline $\begin{array}{l}\text { Non-agricultural } \\
\text { income per person }\end{array}$ & $\begin{array}{l}\text { Total non-agricultural income against the population of } \\
\text { the household }\left(10^{3} \text { yuan/capita }\right)\end{array}$ & 12.19 & 8.79 & 0.00 & 45.00 \\
\hline $\begin{array}{l}\text { Household agricultural } \\
\text { laborer availability }\end{array}$ & $\begin{array}{l}\text { Number of agricultural labor per unit land area of the } \\
\text { household (labor/mu) }\end{array}$ & 0.31 & 0.20 & 0.06 & 1.08 \\
\hline Average age & $\begin{array}{l}\text { Average age of agricultural policy makers of the } \\
\text { household (year) }\end{array}$ & 57.38 & 9.68 & 36.00 & 77.00 \\
\hline Education level & $\begin{array}{l}\text { Average education level of agricultural policy makers of } \\
\text { the household ( } 1=\text { illiterate; } 2=\text { primary school; } 3=\text { junior } \\
\text { middle school; } 4=\text { senior middle school; } 5=\text { college or } \\
\text { above) }\end{array}$ & 2.29 & 0.82 & 1.00 & 5.00 \\
\hline Ratio of laborers & $\begin{array}{l}\text { Ratio between the numbers of laborers and total popula- } \\
\text { tion of the household }\end{array}$ & 0.71 & 0.24 & 0.00 & 1.00 \\
\hline \multicolumn{6}{|l|}{ Village level $(\mathrm{n}=14)$} \\
\hline Distance to city center & $\begin{array}{l}\text { The nearest distance between the village and the city } \\
\text { center }(\mathrm{km})\end{array}$ & 12.17 & 2.90 & 7.91 & 16.28 \\
\hline Land transition rate & $\begin{array}{l}\text { The ratio between the area of transitioned farmland and } \\
\text { the total area of farmland of the village }\end{array}$ & 0.06 & 0.11 & 0.00 & 0.42 \\
\hline $\begin{array}{l}\text { Electricity price for } \\
\text { irrigation }\end{array}$ & $\begin{array}{l}\text { Electricity price for irrigation of the village } \\
\text { (yuan/degree) }\end{array}$ & 0.59 & 0.40 & 0.00 & 1.00 \\
\hline
\end{tabular}

Note: Land quality scales were mainly from the results obtained during the first implementation of the household contract responsibility reforms, and yields of winter wheat were used for corrections among villages. Specifically, yields of winter wheat from good land were larger than $450 \mathrm{~kg} / \mathrm{mu}$, from relatively good land 400-450 kg/mu, from relatively poor land $350-400 \mathrm{~kg} / \mathrm{mu}$, and from poor land less than $350 \mathrm{~kg} / \mathrm{mu}$. For the irrigation condition, irrigated land parcels were those near motor-pumped wells with irrigation equipment available; unirrigated land parcels were those far away from wells, or those near wells without irrigation equipment available. Agricultural equipment refers to agricultural tractors used for transportation of agricultural products.

approach considering multiple factors including opportunity cost, ecological value and stakeholder prospects (Huang et al., 2002). Opportunity cost accounting is widely applied globally for the determination of ecological compensation (Han and Yu, 2014). American's Conversation Reserve Program and China's "Grain for Green" Program are two representative examples (Wan and Zou, 2008).

In this study, opportunity cost accounting was also applied to determine the compensation for household winter wheat abandonment.

$$
O C=\pi_{a}-\pi_{b}=\left\{\begin{array}{c}
\pi_{\mathrm{ww}} \\
\pi_{\mathrm{ww}}+\pi_{\mathrm{sm}}-\pi_{\mathrm{cm}}
\end{array}\right.
$$


where $O C$ is the opportunity cost for household winter wheat abandonment; $\pi_{\mathrm{a}}$ and $\pi_{\mathrm{b}}$ are the net profits of land parcels before and after winter wheat abandonment (yuan/mu), respectively. If the net profits of summer maize and spring maize are equal, $O C$ will roughly equal the net profit of winter wheat $\left(\pi_{\mathrm{ww}}\right.$, yuan/mu). Otherwise, $O C$ will be the difference between the net profit for the double-cropping system $\left(\pi_{\mathrm{ww}}+\pi_{\mathrm{sm}}\right.$, yuan/mu) and the net profit for the single-cropping system ( $\pi_{\mathrm{cm}}$, yuan/mu).

The net profit of a crop can be calculated using cost-benefit analysis:

$$
\pi=p \times Y-I_{\text {seed }}-I_{\text {pesticide }}-I_{\text {fertilizer }}-I_{\text {machinery }}-I_{\text {irrigation }}-I_{\text {labor }}
$$

where $p$ is the price of agricultural products (yuan $/ \mathrm{kg}) ; Y$ is crop yield $(\mathrm{kg} / \mathrm{ha}) ; I_{\text {seed }}, I_{\text {pesticide, }}$, $I_{\text {fertilizer }}, I_{\text {machinery }}, I_{\text {irrigation }}$, and $I_{\text {labor }}$ are the input values of seed, pesticide, fertilizer, machinery, irrigation and labor force (yuan/mu), respectively; and $I_{\text {labor }}$ is usually estimated by multiplying the shadow wage of agricultural laborers ( $W_{l}$, yuan/day) by labor input (Labor, day/mu). According to $\mathrm{Du}$ (2000), $W_{l}$ equals marginal agricultural profit, i.e., increase in total agricultural profit added by the last unit of labor input.

$$
w_{l}=\partial G / \partial L=\gamma \times G / L
$$

where $G$ is total agricultural profit (yuan); $L$ is labor input (days); and $\gamma$ is the elastic coefficient of labor input, which can be estimated using the Cobb-Douglas production function (Du, 2000).

$$
\ln G=\alpha+\beta \times \ln A+\gamma \times \ln L+\theta \times \ln C+\sum(\delta \times Z)+\varepsilon
$$

where $\alpha$ is a constant term; $A, L$ and $C$ refer to land input, labor input and capital input, respectively; $\beta, \gamma$ and $\theta$ are the elastic coefficients of $A, L$ and $C$, respectively; $Z$ refers to a list of external factors, such as farming conditions, climate factors and labor force characteristics; $\delta$ refers to a list of corresponding coefficients; and $\varepsilon$ is the residual term.

\section{Results analysis}

\subsection{Determinants of household cropping system decisions and target parcels for the land fallow policy}

Multi-level logit models were applied to specify the determinants of household cropping system decisions; this was useful for identifying land parcels for winter wheat production and for improving the execution efficiency of the land fallow policy under the condition of households abandoning winter wheat on their own initiative (Xu et al., 2004). Table 2 displays the estimated results of four multi-level models, with different sets of independent variables incorporated.

Model 1 was a random intercept model with no independent variables, also known as the "empty model". This model was usually used as a base model to estimate whether the group level variance of the dependent variable was significant; it was also used to calculate the explanation degrees of the group levels (Overmars and Verburg, 2006). Results of Model 1 showed that the random effect at village level $\left(\operatorname{VAR}\left(\mathrm{u}_{00}\right)\right)$ was significant at the 0.01 level, suggesting a significant difference in household cropping system decisions between villages. In comparison, the random effect at household level $\left(\operatorname{VAR}\left(\mathrm{r}_{0}\right)\right)$ was not significant. The intra-class coefficients at household and village levels were 0.032 and 0.405 , respectively, im- 
plying that $40.5 \%$ of the total variance should be attributed to variation within villages, and only $3.2 \%$ should be attributed to variation within households. Variation within land parcels may explain the remaining $56.2 \%$. Thus, land parcel and village levels were both crucial in explaining variation in household cropping system decisions, with the explanatory degree of the land parcel level being the highest.

Table 2 Results of multi-level logit models for the factors influencing household cropping system decisions

\begin{tabular}{|c|c|c|c|c|}
\hline & Model 1 & Model 2 & Model 3 & Model 4 \\
\hline \multicolumn{5}{|l|}{ Fixed effect } \\
\hline Intercept & -0.008 & -0.050 & -0.009 & 1.984 \\
\hline \multicolumn{5}{|l|}{ Land parcel level $(N=521)$} \\
\hline Plot area & & 0.065 & 0.067 & 0.094 \\
\hline Land quality & & $-0.498 * * *$ & $-0.523 * * *$ & $-0.765 * * *$ \\
\hline Distance to residence & & -0.184 & -0.175 & -0.287 \\
\hline Irrigation conditions & & $3.314 * * *$ & $3.352 * * *$ & $4.630 * * *$ \\
\hline \multicolumn{5}{|l|}{ Household level $(N=134)$} \\
\hline Agricultural equipment & & & $0.466 * *$ & $0.833 * *$ \\
\hline Land fragmentation & & & $-2.153 * *$ & $-3.134 * *$ \\
\hline Non-agricultural income per person & & & $-0.025^{*}$ & $-0.033 *$ \\
\hline Household agricultural laborer availability & & & $2.087 * * *$ & $3.146^{* * *}$ \\
\hline Average age & & & $0.250 * * *$ & $0.344 * *$ \\
\hline Average age squared & & & $-0.002 * * *$ & $-0.003 *$ \\
\hline Education level & & & -0.001 & -0.002 \\
\hline Ratio of laborers & & & 0.366 & 0.619 \\
\hline \multicolumn{5}{|l|}{ Village level $(N=14)$} \\
\hline Distance to city center & & & & 0.017 \\
\hline Land transition rate & & & & $4.762 *$ \\
\hline Electricity price for irrigation & & & & $-4.016^{* * *}$ \\
\hline \multicolumn{5}{|l|}{ Random effect } \\
\hline \multicolumn{5}{|l|}{ Household level } \\
\hline $\operatorname{VAR}\left(\mathrm{r}_{0}\right)$ & 0.180 & 0.530 & 0.060 & 0.120 \\
\hline$\rho_{2}$ & 0.032 & 0.074 & 0.008 & 0.031 \\
\hline \multicolumn{5}{|l|}{ Village level } \\
\hline $\operatorname{VAR}\left(\mathrm{u}_{00}\right)$ & $2.265^{* * *}$ & $3.444 * * *$ & $4.317 * * *$ & $0.659 * * *$ \\
\hline$\rho_{3}$ & 0.405 & 0.484 & 0.574 & 0.168 \\
\hline ROC & 0.846 & 0.920 & 0.913 & 0.915 \\
\hline
\end{tabular}

Note: ${ }^{*} p<0.1 ;{ }^{* *} p<0.05 ;{ }^{* * *} p<0.01$.

Model 2 incorporated independent variables at land parcel level. Results showed that land quality and irrigation condition both significantly influenced household cropping system decisions, while the influences of plot area and distance to residence were not significant. In Model 3, the coefficients for the independent variables at land parcel level had consistent signs, and the changes in their magnitudes were minor compared to those in Model 2. For the independent variables at household level, agricultural equipment and household agricul- 
tural laborer availability were both positively correlated with household preference for the double-cropping system, while land fragmentation and non-agricultural income per person showed a negative correlation. The age of agricultural policy makers showed a non-linear relationship with household cropping system decisions, as the estimated coefficients for average age and average age squared were both significant and showed opposite effects. Additionally, education level and ratio of laborers did not show significant influence on household cropping system decisions. Results of Model 4 showed similar relationships between the independent variables and the dependent variable at land parcel and household levels, as for Model 2 and Model 3. For the independent variables at village level, electricity price for irrigation was negatively correlated with the probability of households choosing the double-cropping system, while the influence of land transition rate was positive. Considering that the average land transition rate in Cangxian was only $6 \%$, the influence was limited. A third variable at village level, i.e., distance to city center, showed non-significant influence on household cropping system decisions.

Multi-level logit analysis revealed that land parcel contexts were most important in explaining whether households chose a double-cropping system or a single-cropping system, and the explanatory degree was $56.2 \%$. Village environment could also explain $40.5 \%$ of the variance in household cropping system decisions, which was less than that at land parcel level. However, household characteristics affected household decisions in only a minor way. The ROC value was the highest in Model 2, implying that the multi-level logit model incorporating the independent variables at only the land parcel level realized the optimal estimation fitting effect.

In terms of the specific effects of land quality and irrigation condition on household cropping system decisions, households were more likely to choose a double-cropping system on land parcels of better land quality; the percentages of sown areas farmed using the double-cropping system all exceeded $50 \%$ for good land, relatively good land and relatively poor land (Figure 2). For different irrigation conditions, the probability of a household choosing a double-cropping system was much larger on irrigated land than on unirrigated land. The percentage of sown areas farmed using the double-cropping system was only $9.2 \%$ on unirrigated land, while it reached $62.5 \%$ on irrigated land (Figure 3). Therefore, we suggest that the target land parcels for the land fallow policy should be irrigated with good, relatively good or relatively poor land quality, and land parcels with the above properties should be proposed to abandon winter wheat with reasonable and proper compensation.

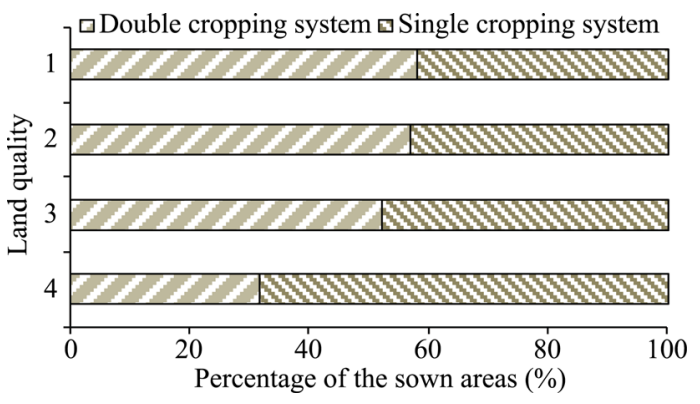

Figure 2 Land qualities and the percentages of sown areas for the two cropping systems

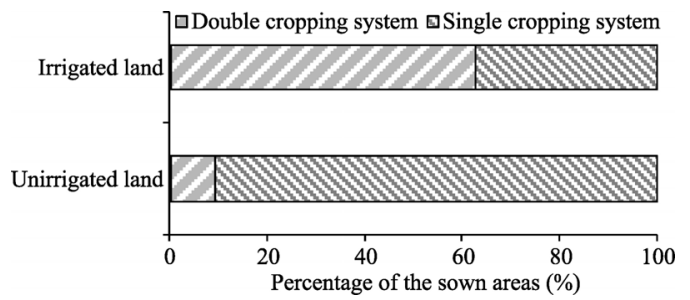

Figure 3 Irrigation conditions and the percentages of sown areas for the two cropping systems 


\subsection{Determination of standards for ecological compensation}

\subsubsection{Shadow wage of agricultural laborers}

The Cobb-Douglas production function was estimated using household survey data. The dependent variables were the logarithmic forms of household total agricultural profits, including profits for winter wheat, summer maize and spring maize. The OLS method was applied in estimating the parameters using Stata software. The results are shown in Table 3.

Table 3 Estimation results of the Cobb-Douglas production function

\begin{tabular}{lccc}
\hline \multicolumn{1}{c}{ Variable name } & Coefficient & t-value & P-value \\
\hline Constant & $7.000^{* * *}$ & 49.85 & 0.000 \\
$\ln$ (total sown area) & $0.901^{* * *}$ & 19.44 & 0.000 \\
$\ln$ (total labor input) & $0.099^{* *}$ & 2.08 & 0.040 \\
Ratio of areas of good/relatively good land & $0.150^{* * *}$ & 3.05 & 0.003 \\
Ratio of areas damaged by disasters & $-0.517^{* * *}$ & -10.78 & 0.000 \\
Average age of agricultural policy makers & $-0.003^{*}$ & -1.68 & 0.095 \\
Education level of agricultural policy makers & -0.006 & -0.29 & 0.770 \\
Ratio of male laborers in agriculture & -0.008 & -0.13 & 0.893 \\
$N$ & & 134 & 0.914 \\
Adjusted $R^{2}$ & & \\
\hline
\end{tabular}

Note: ${ }^{*} \mathrm{p}<0.1 ;{ }^{* *} \mathrm{p}<0.05 ;{ }^{* * *} \mathrm{p}<0.01$.

According to Table 3, adjusted $R^{2}=0.914$, implying that the model provided a good fit to the real data. The elastic coefficient of total labor input was 0.099 , and the average shadow wage for agricultural laborers of Cangxian in 2014 could be calculated using Equation (5). The calculated result was 46.8 yuan/day. Then the net profits of winter wheat, summer maize or spring maize in each land parcel were calculated using Equation (4). Additionally, there was strong collinearity between $\ln$ (total sown area) and $\ln$ (total capital input), with the correlation coefficient being 0.952 . The variable $\ln$ (total capital input) was discarded from the model.

\subsubsection{Contrast of the net profits between spring maize and summer maize}

It was impossible to simultaneously obtain the net profits of spring maize and summer maize for the same land parcel, while the net profits of spring maize and summer maize in land parcels with similar farming conditions could be regarded as substitutions. An independent-sample t-test was applied to compare the net profits of the two crops. Results are shown in Tables 4 and 5 .

Table 4 Results of an independent-sample t-test for land parcels with different irrigation conditions

\begin{tabular}{|c|c|c|c|c|c|c|c|c|}
\hline \multirow{2}{*}{ Crop type } & \multicolumn{4}{|c|}{ Irrigated land } & \multicolumn{4}{|c|}{ Unirrigated land } \\
\hline & $\mathrm{N}$ & Mean & t-value & P-value & $\mathrm{N}$ & Mean & t-value & P-value \\
\hline Spring maize & 30 & 593.82 & \multirow{2}{*}{1.233} & \multirow{2}{*}{0.220} & 63 & 619.13 & \multirow{2}{*}{-0.513} & \multirow{2}{*}{0.609} \\
\hline Summer maize & 83 & 648.76 & & & 53 & 594.39 & & \\
\hline
\end{tabular}

Note: We ignored land parcels which suffered from serious disaster attacks. 
Table 5 Results of an independent-sample t-test for land parcels with different land qualities

\begin{tabular}{|c|c|c|c|c|c|c|c|c|}
\hline \multirow{2}{*}{ Crop type } & \multicolumn{4}{|c|}{ Good land } & \multicolumn{4}{|c|}{ Relatively good land } \\
\hline & $\mathrm{N}$ & Mean & t-value & $P$ value & $\mathrm{N}$ & Mean & t-value & $P$ value \\
\hline Spring maize & 34 & 746.68 & \multirow{2}{*}{-1.064} & \multirow{2}{*}{0.290} & 22 & 654.00 & \multirow{2}{*}{-0.475} & \multirow{2}{*}{0.637} \\
\hline Summer maize & 66 & 696.26 & & & 42 & 630.26 & & \\
\hline \multirow{2}{*}{ Crop type } & \multicolumn{4}{|c|}{ Relatively poor land } & \multicolumn{4}{|c|}{ Poor land } \\
\hline & $\mathrm{N}$ & Mean & t-value & $\mathrm{P}$-value & $\mathrm{N}$ & Mean & t-value & P-value \\
\hline Spring maize & 25 & 550.75 & \multirow{2}{*}{-0.756} & \multirow{2}{*}{0.454} & 12 & 272.96 & \multirow{2}{*}{-0.459} & \multirow{2}{*}{0.653} \\
\hline Summer maize & 23 & 510.41 & & & 5 & 237.31 & & \\
\hline
\end{tabular}

Note: We ignored land parcels which suffered from serious disaster attacks.

Results of the independent-sample t-test showed that there were no significant differences in the net profits between spring maize and summer maize on land parcels with the same irrigation conditions. For irrigated land and unirrigated land, P-values both exceeded 0.1 (Table 4). In addition, the net profits of spring maize and summer maize were close to each other on land parcels with the same land quality. The P-value for good land was the lowest, also exceeding 0.1. Generally, despite different growing periods for spring and summer maize, differences in the net profits between the two crops were not significant under similar farming conditions. According to Equation (3), the opportunity cost of household winter wheat abandonment roughly equaled the net profit of winter wheat.

\subsubsection{Opportunity cost and compensation standards for winter wheat}

Section 3.1 revealed that household initial winter wheat abandonment accounted for about $70 \%$ of sown areas of poor land and more than $90 \%$ of sown areas of unirrigated land. Winter wheat was mainly grown on good, relatively good or relatively poor irrigated land parcels, which were also suggested target land parcels for the land fallow policy. The net profits of winter wheat on the above land parcels were calculated using Equation (4). Results are shown in Figure 4.

According to Figure 4, the cumulative percentages of sown areas of winter wheat changed in different ways for good, relatively good and relatively poor irrigated land. The cumulative percentages were approximately equal when the net profits of winter wheat were less than $100 \mathrm{yuan} / \mathrm{mu}$. When the net profits ranged between $100 \mathrm{yuan} / \mathrm{mu}$ and $250 \mathrm{yuan} / \mathrm{mu}$, the cumulative percentages for good and relatively good irrigated land were still similar, and were all lower than those for relatively poor irrigated land. When the net profits were between 250 yuan/mu and 600 yuan/mu, the cumulative percentages for three types of irrigated land were different from each other; the cumulative percentages for good land were lower than those for relatively good land, and the cumulative percentages for relatively poor land were the highest. When the net profits exceeded 600 yuan/mu, the cumulative percentages were again similar for the three types of irrigated land. For all irrigated land, the cumulative percentages were lower than those for relatively poor land and were higher than those for good land; the cumulative percentages equaled those for relatively good land when net profits exceeded 400 yuan/mu. 


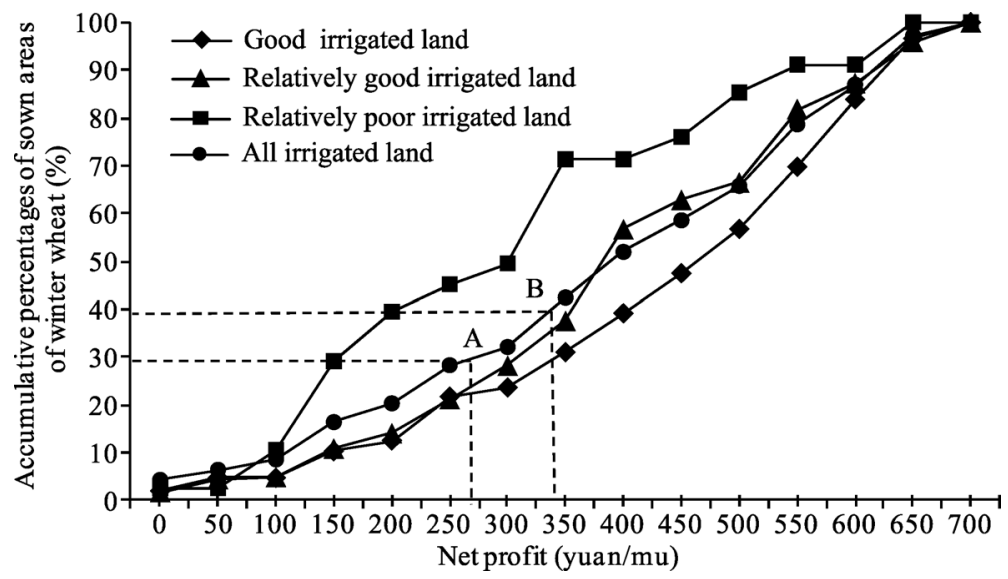

Figure 4 Land quality, net profit and cumulative percentage of the sown areas of winter wheat

Compensation standards were usually determined based on the mean values of opportunity cost in previous instances of ecological compensation (Wan and Zou, 2008). In Cangxian, the mean values of the net profits of winter wheat were $424 \mathrm{yuan} / \mathrm{mu}, 380$ yuan/mu and 291 yuan/mu for good irrigated land, relatively good irrigated land and relatively poor irrigated land, respectively. For all irrigated land, the mean value was 367 yuan/mu. Suppose that households would abandon winter wheat only if their subsidy exceeded net profit, and the accumulated percentages of sown areas of winter wheat in Figure 4 are regarded as accumulated percentages of winter wheat abandonment for different subsidies, i.e. net profits. For all irrigated land, the accumulated percentage of winter wheat abandonment would be $31.2 \%$ if the subsidy was equal to the mean value of net profits of winter wheat for relatively poor land (291 yuan/mu); the accumulated percentages of winter wheat abandonment would be $46.0 \%$ and $55.0 \%$ if subsidies were equal to the mean values for relatively good land (367 yuan/mu) and good land (424 yuan/mu), respectively. Therefore, the potential accumulated percentages of winter wheat abandonment would change a lot under different levels of compensation standards, and the specific amounts of compensation subsidy should be determined according to the percentages of winter wheat abandonment proposed by the government.

There has been no definite rule about sown areas or percentage of winter wheat abandonment in the groundwater over-exploited NCP. Hu et al. (2010) proposed that the percentage reduction in amount of local groundwater withdrawal should be no less than $29.2 \%$ in order to stop groundwater drawdown, and it should be more than $39.2 \%$ in order to induce groundwater recovery and restoration to the pre-development hydrologic conditions of the mid-1950s. Considering only the groundwater consumption of winter wheat, the above two thresholds of $29.2 \%$ and $39.2 \%$ were also used to determine the percentages of winter wheat abandonment, since the percentage shrinkage in sown areas of winter wheat approximately equaled the percentage reduction in groundwater consumption in the NCP (Wang et al., 2015). The corresponding net profits were $273 \mathrm{yuan} / \mathrm{mu}$ and $341 \mathrm{yuan} / \mathrm{mu}$, respectively (Figure 4). Accordingly, at the preliminary stage, groundwater recovery and restoration are the primary purposes of the land fallow policy, and a higher level of 350 yuan/mu should be recommended as the subsidy for ecological compensation, similar to the mean value of net profits of winter wheat on all irrigated land. Later, when the major aim of the land fallow 
policy is transitioned to balancing groundwater exploitation and supplementation, 280 yuan/mu should be the recommended subsidy for ecological compensation, which approximately equals the mean value of net profits of winter wheat on relatively poor irrigated land.

\section{Discussion}

The subsidy of ecological compensation determined in the documentation The Implementation Program on Pilot Comprehensive Control of Groundwater Over-exploitation in Hebei Province through Agricultural Cropping Structure Adjustments and Water-saving Projects in 2014 was 500 yuan/mu. This value was determined with insufficient scientific basis, and has not been widely implemented. In this study, subsidies of ecological compensation were recommended based on determinants analysis of household cropping system decisions and estimation of opportunity costs for winter wheat abandonment, using household survey data. Following the above scientific basis, the two subsidy values, i.e., 350 yuan $/ \mathrm{mu}$ and 280 yuan/mu, were both lower than 500 yuan/mu, implying a large reduction in financial input and positive policy implications. However, further work is still needed: for example, to enlarge the range of case-study areas and the tracking survey, in order to achieve more reasonable standards for ecological compensation.

Additionally, groundwater over-exploitation is the main negative ecological effect of winter wheat production in the NCP, apart from the excessive application of pesticides, fertilizer and so on. Winter wheat production also has positive ecological effects, such as purifying air, preserving soil and water, etc.

\section{Conclusions}

The main conclusions can be drawn as follows:

(1) The contexts of land parcels and village background were both crucial in explaining household cropping system decisions, and their explanation degrees on the variances of the independent variable were $56.2 \%$ and $40.5 \%$, respectively. The explanation degree for household characteristics was only $3.2 \%$. The multi-level logit model incorporating independent variables at only the land parcel level was able to realize the optimal estimation fitting effect $(\mathrm{ROC}=0.920)$.

(2) Winter wheat abandonment accounted for about $70 \%$ of the sown areas of poor land and more than $90 \%$ of the sown areas of unirrigated land. Winter wheat was mainly grown on irrigated land or land with good, relatively good or relatively poor qualities. Target land parcels for the land fallow policy should be the good, relatively good and relatively poor irrigated ones.

(3) There were no significant differences in net profits between spring and summer maize, under similar farming conditions. The opportunity cost for household winter wheat abandonment should be equal to the net profit of winter wheat.

(4) A higher level of $350 \mathrm{yuan} / \mathrm{mu}$ was recommended as a subsidy for ecological compensation at the preliminary stage of the land fallow policy, when the primary purpose is groundwater recovery and restoration; a lower level of $280 \mathrm{yuan} / \mathrm{mu}$ was recommended for a later stage when the major aim of the land fallow policy transitions to balancing groundwater exploitation and supplementation. 


\section{References}

Cao G, Zheng C, Scanlon B R et al., 2013. Use of flow modeling to assess sustainability of groundwater resources in the North China Plain. Water Resources Research, 49(1). doi: 10.1029/2012wr011899.

Chen J Y, Tang C Y, Shen Y J et al., 2003. Use of water balance calculation and tritium to examine the dropdown of groundwater table in the piedmont of the North China Plain (NCP). Environmental Geology, 44(5): $564-571$.

Du Y, 2000. Effects of shadow wage rate on the labor supply of farmers household: An empirical study of household labor allocation in poor areas. China Rural Survey, (5): 36-42. (in Chinese)

Feng Z M, Liu D W, Zhang Y H, 2007. Water requirements and irrigation scheduling of spring maize using GIS and CropWat model in Beijing-Tianjin-Hebei region. Chinese Geographical Science, 17(1): 56-63.

General Office of Hebei Provincial Government and Statistical Bureau of Hebei Province (GOHPG/SBHP), 2014. Hebei Rural Statistical Yearbook 2014. Beijing: China Statistics Press, 489-491. (in Chinese)

Gleeson T, Wada Y, Bierkens M F P et al., 2012. Water balance of global aquifers revealed by groundwater footprint. Nature, 488(7410): 197-200.

Han H, Yu Y, 2014. Research on the payment for environmental services of the 'Grain for Green' program: Cost basis, willingness to accept or environmental values (IAE). Issues in Agricultural Economy, (4): 64-73. (in Chinese)

Hu Y, Moiwo J P, Yang Y et al., 2010. Agricultural water-saving and sustainable groundwater management in Shijiazhuang Irrigation District, North China Plain. Journal of Hydrology, 393(3/4): 219-232.

Huang F, Kang M, Zhang X, 2002. The economic compensation strategy in the process of turning cultivated land back into forests and grasslands (TCFG). Acta Ecologica Sinica, 22(4): 471-478. (in Chinese)

Huang J, Bradley G R, Xu C C et al., 2012. Cropping pattern modifications change water resource demands in the Beijing metropolitan area. Journal of Integrative Agriculture, 11(11): 1914-1923.

Kou Q, 2014. The North China Plain suffers severe groundwater over-exploitation and becomes the largest groundwater depression cone of the world. Chinese Radio Network, http://www.radio.cn/. (in Chinese)

Laurans Y, Lemenager T, Aoubid S, 2012. Payments for ecosystem services: From theory to practice. What are the prospects for developing countries? France, Agence Francaise de Developpement, 10-22.

Li J, Inanaga S, Li Z et al., 2005. Optimizing irrigation scheduling for winter wheat in the North China Plain. Agricultural Water Management, 76(1): 8-23.

Li X, 2014. The 'Grain for Green' program: Good deeds turning to bad ones? http://lixiubin.blog.hexun.com/ 1259788_d.html. (in Chinese)

Overmars K P, Verburg P H, 2006. Multilevel modelling of land use from field to village level in the Philippines. Agricultural Systems, 89(2/3): 435-456.

Snijders T A B, Boksker R J, 1999. Multilevel Analysis: An Introduction to Basic and Advanced Multilevel Modelling. New York: Sage, 28-33.

Su S, Zhou X, Wan C et al., 2016. Land use changes to cash crop plantations: Crop types, multilevel determinants and policy implications. Land Use Policy, 50: 379-389.

Sun H, Shen Y, Yu Q et al., 2010. Effect of precipitation change on water balance and WUE of the winter wheat-summer maize rotation in the North China Plain. Agricultural Water Management, 97(8): 1139-1145.

Sun Q, Kröbel R, Müller T et al., 2011. Optimization of yield and water-use of different cropping systems for sustainable groundwater use in North China Plain. Agricultural Water Management, 98(5): 808-814.

Wan B, Zou S, 2008. Practice of Payments for Environmental Services: Case Studies and Explorations. Beijing: China Environmental Science Press, 71-196. (in Chinese)

Wang W. 2012. Hebei Geography. Beijing: Beijing Normal University Press, 23-37. (in Chinese)

Wang X, Li X, Fischer G et al., 2015. Impact of the changing area sown to winter wheat on crop water footprint in the North China Plain. Ecological Indicators, 57: 100-109.

Wang X, Li X, Xin L, 2014. Impact of the shrinking winter wheat sown area on agricultural water consumption in the Hebei Plain. Journal of Geographical Sciences, 24(2): 313-330.

Xu J, Ran T, Xu Z, 2004. Sloping land conversion program: Cost-effectiveness, structural effect and economic sustainability. China Economic Quarterly, 4(1): 139-162. (in Chinese)

Yang W, Chen H, Yang M et al., 2010. Analysis of the factors of the land use decision-making of households based on a multi-level model: A case study of Gaoxigou village, Mizhi County, Shaanxi Province. Journal of Natural Resources, 25(4): 646-656. (in Chinese)

Zhang B, Zhang F, Qu B et al., 2015. Rural non-agricultural differences and their driving forces at the county level: A case study of 16 villages in Yishui, Shandong, East China. Acta Geographia Sinica, 70(6): 1008-1021. (in Chinese)

Zhang Y, Li X, Song W, 2014. Determinants of cropland abandonment at the parcel, household and village levels in mountain areas of China: a multi-level analysis. Land Use Policy, 41: 186-192.

Zhang Z, Fei Y, Chen Z et al., 2009. Evaluation of the Groundwater Sustainable Utilization and Survey in the North China Plain. Beijing: Geological Publishing House, 1-9. (in Chinese) 